ALDABA (1985 - 2015) 


\title{
ALDABA (1983-2015). ÍNDICES DE LA REVISTA, Nº 1 A 40
}

\author{
Sonia Gámez Gómez \\ Coordinadora del COIE \\ Profesora tutora \\ de Métodos y técnicas de investigación histórica \\ en el Centro UNED Melilla
}

El número 40 de la revista Aldaba representa la trayectoria existosa de una iniciativa que el Centro UNED-Melilla puso en marcha en el otoño de 1983. Este número refleja una renovada etapa de firme consolidación que, actualmente, se beneficia de un reconocido prestigio y una amplia andadura que posiciona a esta revista en un puesto merecido en el campo de la investigación.

Este capítulo pretende exponer aquellas cuestiones que han sido tratadas en la revista Aldaba a lo largo de toda su trayectoria. A partir de una exposición cronológica de los índices de cada número se apreciará la variedad temática, debates y reflexiones que han dinamizado la publicación. Del mismo modo, evidencia la amplia participación de investigadores, profesores o especialistas que forman parte de la historia de la revista del Centro UNED-Melilla.

Finalmente, un índice general de autores cierra el capítulo. Esta relación alfabética facilitará la consulta de todas las personas que han colaborado con sus artículos, cuyas investigaciones han sido el soporte fundamental de una publicación que hoy alcanza el número 40. De los autores y sus estudios se nutre la Aldaba y es intención de esta revista continuar incrementando la participación, diversificar hacia nuevas áreas de pensamiento y seguir cumpliendo con el nivel académico y científico que con los años ha adquirido.

\section{Índice General Cronológico}

Aldaba, Revista del Centro Asociado a la UNED de Melilla, no 1 , octubre-noviembre de 1983.

Consejo de Redacción, "Presentación"

Estudios:

Sultana Wahnón Bensusan, "La historicidad de la poesía de Miguel Fernández”, 1-16.

Ana María Riaño López, "Transcripción y breve estudio de una versión en ladino del libro de Rut", 17-26.

María Isabel Montoya Puertas, "Sobre el arte de la caza”, 27-34.

José Manuel Calzado Puertas, “El láser en la industria química del futuro”, 35-43. 
Encarna Cabello, “Descripción del medio marroquí en Madrid” 45-51.

Guillermo Orozco Pardo, “La cárcel como instrumento de la violencia institucional”, 53-61.

Dolores Aguirre García, “Arte Hispano-Musulmán del siglo X: El arte califal”, 63-75.

Temas de Melilla:

Francisco Saro Gandarillas, "Melilla: Cien años de hallazgos arqueológicos”, 77-84.

Reseñas bibliográficas:

Teresa Rizo Gutiérrez, "R. Fernández Ballesteros y J.A.I. Carrobles, Evaluación conductual o metodología y aplicaciones”, 85-86.

Alicia Benarroch, "Albert Einstein y Leopold Infeld, La física, aventura del pensamiento”, 86-88.

\section{Aldaba, Revista del Centro Asociado a la UNED de Melilla, n 2, 1984.}

Carlos Collado Mena, "Reflexiones sobre el constitucionalismo español y la Constitución de 1978", 7-29.

Francisco Samaranch Kirner, "Sentido y alcance del anti-idealismo de Ortega y Gasset", 31-44.

Marta Mata, "Renovación pedagógica”, 45-60.

Encarnación Varela, “Una aproximación hispánica a Debora Barón”, 61-69.

Simón Benguigui Levy y Miguel García Carrascosa, "Historia geológica de la Luna”, 71-83.

Javier Gutiérrez Pellejero, “Aproximación al Impuesto sobre el Patrimonio Neto”, 85-108.

Vicente Moga Romero, "Melilla en la visión de la novela histórica: 1921(Aproximación en tres textos)”, 109-121.

María del Carmen Marcos Casquero, “Acercamiento a la Sociolingüística”, 123-131.

Reseñas bibliográficas:

Gómez Bernardi, J. Ma “'A. Ortega. Reglamento del Impuesto sobre Sociedades. Ingresos y gastos”, 135.

Vicente Moga Romero, “D. Cantimori. Humanismo y religiones en el Renacimiento”, 135- 138 .

Aldaba, Revista del Centro Asociado a la UNED de Melilla, no 3, 1984. Coordinador de este número Vicente Moga Romero.

Vicente Moga Romero, "Introducción: “Aldaba” versus Melilla, 1984", 7-9.

Laura Cantón Fernández y Ana Riaño López, “El ámbito modernista de Melilla”, 11-25. 
Francisco Saro Gandarillas, "Municipalidad y Administración Local, antecedentes de la Constitución del Ayuntamiento de Melilla”, 27-40.

Santiago Domínguez, "Breve historia de las Islas Chafarinas”, 41-50.

José Manuel Cabo Hernández, "Laridos y aves marinas de las aguas de Melilla”, 51-66.

Juan Antonio González García, “La Mar Chica: un extraño ecosistema”, 67-72.

Henk Driessen, "Preludio a un estudio de Melilla: la perspectiva de un “outsider"”, 73-78.

Ricardo Crespo, “Algunos aspectos del Quijote”, 79-88.

Retazos históricos:

León Levy, "El expediente Picasso”, 89-92.

Reseñas bibliográficas:

Miguel Fernández, “Encarna León: Este caudal de mis palabras mudas”, 93.

Laura Cantón, "Sultana Wahnon: El irracionalismo en la poesía de Miguel Fernández”, 94.

Aldaba, Revista del Centro Asociado a la UNED de Melilla, no 4, 1985.

José Megías Aznar, “Una lectura de la trilogía rural de Federico García Lorca”, 7-34.

Miguel Molina Martínez, "Claves de interpretación de la realidad hispanoamericana”, 35-46.

Soledad Ballesteros Jiménez, "La posibilidad de mejorar científicamente la inteligencia”, 47-62.

Pedro J. Perales Larios, “José M. Álvarez de Sotomayor, un poeta olvidado”, 63-72.

Feliciano Delgado, “Maimónides, pensamiento, influencia y actualidad”, 73-88.

José Luis Fernández de la Torre, "Para una lectura de El Mago”, 89-92.

Tema de Melilla:

Antonio Bravo Nieto, “Algunos aspectos de la proclamación de la República en Melilla: abril elecciones Municipales, 1931”, 93-110.

Reseñas bibliográficas:

Vicente Moga Romero, "Manuel Moreno Fraginals: La historia como arma y otros estudios sobre esclavos, ingenios y plantaciones”, 111-112.

Ana María Riaño López, “José Amador de los Ríos: Historia social, política y religiosa de los judíos de España y Portugal”, 112-114.

Aldaba, Revista del Centro Asociado a la UNED de Melilla, $\mathbf{n}^{\circ}$ 5, 1985. Coordinador de este número Vicente Moga Romero.

I Introducción

Vicente Moga Romero, coordinador del n 5, "Escribir nuestra historia", 7-9. 


\section{Estudios}

Claudio A. Barrio y Fernández de Luco. Dibujos Juan Carlos Feliú, "Proto-historia melillense: Fenicios y Cartagineses”, 11-21.

Francisco Saro Gandarillas, "La expansión urbana de Melilla: aproximación a su estudios”, 23-35.

Antonio Bravo Nieto. Dibujos Jesús M. Sáez Cazorla, “Aproximación a un estudio sobre lo ornamental en la arquitectura de Melilla. El barrio del Real: un ejemplo de la impronta modernista”, 35-53.

Ginés Sanmartín Solano, “La Compañía Española de Minas del Rif (1907-1984)”, 55-74.

Juana Alias Rodríguez, "Melilla en el período comprendido entre febrero y julio de 1936", 75-82.

Marcos M. García Velasco. Guillermo Sarmiento Zea. Alejandro del Canto Bossini, “Análisis estructural del comercio en Melilla”, 83-95.

III Melilla en la Dictadura de Primo de Rivera

José Javier González Sánchez, “El proceso Berenguer: sus efectos en Melilla”, 97-106.

Paulina Morala Martínez, "Reformas de la Administración Local durante la Dictadura: de la Junta de Arbitrios a la Junta Municipal (1923 - 1927)”, 107-120.

María Josefina García Alonso, "La enseñanza en Melilla durante la Dictadura de Primo de Rivera”, 121-132.

Francisca González Sorroche, “El somatén. Su formación en Melilla (1923 - 1929)”, 133-154.

Rosa María Montero Madrid, "La catástrofe de Cabrerizas (Melilla, 26 de septiembre de 1928)", 155-168.

IV Fuentes para el estudio de la historia de Melilla

Vicente Moga Romero, "Fuentes hemerográficas para la historia de Melilla: La hemeroteca Municipal de Madrid”, 169-190.

Jesús F. Salafranca Ortega, "Fuentes documentales para la historia de Melilla. La Vicaría de África del Archivo Diocesano de Málaga”, 191-197.

V Retazos

León Levy, "La colectividad judía en Melilla”, 199-203.

VI Reseñas bibliográficas

RafaelYus Ramos y José Manuel Cabo Hernández, "RafaelYus Ramos y José Manuel Cabo Hernández. Didáctica de las Ciencias Naturales en marco extraescolar”, 205.

Ana Riaño, “A.M. Riaño López, M.J. Macarro Heredia, M.C. Escribano de la Cal, M.T. Rizo Gutiérrez y M. Domínguez Puente. Estudio demográfico y sociológico de la Tercera Edad en Melilla”, 205-207. 
Aldaba, Revista del Centro Asociado a la UNED de Melilla, nº 6, 1986.

José Muñoz Domínguez, "La fiscalidad de los territorios de Ceuta y Melilla”, 7-30.

Joaquín Rodríguez Puget, “Los ingenieros militares en el urbanismo de Melilla”, 31-46.

Federico Cristófol de Alcaraz, "La protección de los consumidores y usuarios en materia de precios", 47-50.

Jesús Leonardo González Vázquez, “Louis Aragón: Intelectuales españoles y la Guerra Civil", 51-56.

Simón Benguigui Levy, "Morfología Funcional en cefalópodos y trilobites”, 57-62.

Gonzalo Miragaya García y Alicia Benarroch Benarroch, "Aprovechamiento de los lodos urbanos en la agricultura”, 63-70.

Juan José Sánchez de Horcajo, “Autoestima socio profesional del maestro rural”, 71-81.

\section{Aldaba, Revista del Centro Asociado a la UNED de Melilla, no 7, 1987.}

E. Martín, "Introducción”, 6

Eustaquio Martín Rodríguez, "La desorganización organizada en la teoría educativa. Hacia un nuevo realismo pedagógico”, 7-20.

Sara Morgenstern de Finkel, "La crisis del Narcisismo en la teoría educativa. Hacia un nuevo realismo pedagógico”, 21-28.

Ana Sacristán Lucas, “En torno al currículum oculto”, 29-36.

Teresa Bardisa, "La dirección de centros educativos: un problema”, 37-46.

Jurjo Torres Santomé, “La evaluación cualitativa en educación”, 47-60.

Roberto Aparici Marino, “Innovación educativa y alfabetización audiovisual”, 61-66.

\section{Aldaba, Revista del Centro Asociado a la UNED de Melilla, nº 8, 1987.}

José María González Ruíz, "El intelectual y el compromiso religioso en una sociedad democrática”, 7-16.

Carlos Moya, "El intelectual y el compromiso docente en una sociedad democrática”, 17-22. Juan Guerrero Zamora, “Teatro, televisión, cultura y otras manzanas (con o sin gusano) en la misma cesta”, 23-36.

Hermógenes Sáinz, “Televisión y literatura”, 37-42.

Rocío Gutiérrez González, "Nacionalismos en el Maghreb”, 43-54.

León Levy, “Un viajero medieval. Benjamín de Tudela”, 55-58. 
Aldaba, Revista del Centro Asociado a la UNED de Melilla, no 9, 1987, dedicado a: Monográfico sobre Melilla. Coordinador de este número Vicente Moga Romero.

I Introducción

José Megías Aznar, “Aldaba-Melilla: llamar a la puerta de la Historia”, 14-19.

II Estudios

Eloy Martín Corrales, “Aproximación al estudio del corsarismo español en el litoral norteafricano en el siglo XVIII”, 25-40.

Carlos Posac Mon, "Melilla celebra en 1820 el restablecimiento de la Constitución de Cádiz", 41-54.

Jesús F. Salafranca Ortega, "Síntesis histórica de la población judía de Melilla (1497-1936)", 55-70.

III Monográficos

Masonería

José Antonio Ferrer Benimeli, "Tres documentos y situaciones de la Masonería en Melilla y Tetuán”, 71-82.

Manuel de Paz Sánchez; Adoración Perpén Rueda, Luis González Duque; Vicente Moga Romero y Ramón Felipe González, "La supuesta influencia político-ideológica de la Masonería española a través de testimonios norteafricanos: comentarios a una visión sesgada”, 83-96.

Arqueología

Enrique González Cravioto, "Economía de la ciudad antigua de Rusadir”, 97-120.

Carlos Posac Mon, “Las perspectivas arqueológicas de Melilla”, 121-126.

Rafael Fernández de Castro y Pedrera, “La necrópolis púnica y romana de Melilla”, 127-138.

Modernismo

Claudio Barrio Fernández de Luco, “Arquitectura en la Melilla Moderna”, 139-142.

Francisco Saro Gandarillas, “Algo sobre Enrique Nieto”, 143-148.

Antonio Bravo Nieto, "La decoración en fachadas como determinante básico de la arquitectura melillense", 149-154.

Juana Alias Rodríguez, "Breve estudio de la Iglesia Castrense de la Purísima Concepción”, 155-160.

IV Notas

Jesús Sáez Cazorla, “La maqueta de Melilla de León Gil de Palacio (1846)”, 161-166.

José Salvador Miras, “Factores y dinámica atmosférica del clima de Melilla”, 167-176. 
V Textos para la Historia de Melilla

Luis Morales y Reyes, "Descripción de las funciones ejecutadas en la Plaza de Melilla en celebridad del juramento que han prestado sus guarniciones, empleados y vecinos a la Constitución política de la Monarquía española, formada por un ciudadano, amante y fiel observador de este sagrado código”, 177-188.

Vicente Moga Romero, edición, introducción y notas, "Melilla \& Plazas Menores (Chafarinas; Vélez de la Gomera; Alhucemas) en el Diccionario Geográfico-Estadístico-Histórico de España y sus posesiones de ultramar”, 189-224.

Aldaba, Revista del Centro Asociado a la UNED de Melilla, nº10, 1988.

Francisco Javier Yuste Grijalba, “Concepto de Salud”, 7-18.

María Pinto Molina, "Las técnicas documentales en el proceso de aprendizaje”, 19-28.

Ángel Granda Vera, "Distribución y habitar de las algas de las costas de Melilla”, 29-38.

María Teresa Gilbert Maceda, "Edith Sitwell (1887 - 1964)”, 39-44.

Mª Antonia Álvarez Calleja, “¿Autobiografía o ficción?”, 45-48.

Julián Morales Navarro, “Antecedentes Históricos de la Sociología del conocimiento”, 49-67.

\section{Aldaba, Revista del Centro Asociado a la UNED de Melilla, n¹1, 1988.}

Soledad Ballesteros Jiménez, Directora de las Jornadas, "Presentación del número monográfico de la revista Aldaba dedicado a las jornadas de psicología”, 7-9.

José Luis Pinillos, “La Psicohistoria y el Naturalismo Psicológico”, 11-24.

José Luis Fernández Trespalacios, “El conexionismo”, 25-40.

Juan Mayorga, “Unidad y diversidad en la Psicología”, 41-68.

Soledad Ballesteros Jiménez, "Psicología básica y Psicología aplicada”, 69-82.

Helio Carpintero, “La psicología en España, ciencia y profesión”, 83-92.

José Luis Pinillos,--"Lección magistral de apertura del curso 87/88", 93-102.

\section{Aldaba, Revista del Centro Asociado a la UNED de Melilla, nº12, 1988.}

Ana María Riaño López, “Acerca de la poesía israelí contemporánea: Zelda Mishkovsky”, 7-14.

Manuel Suances Marcos, "La aportación de Seneca al estoicismo romano”, 15-20.

María Antonia Álvarez, “Raíces europeas en la obra de Henry James”, 21-24.

Carmen Camero Pérez, "Duración y ritmo en la "nouvelle” de entreguerras”, 25-34. 
Isabel Gutiérrez Román, “Juan Ramón Jiménez, perfil biográfico y poético”, 35-46.

Ana Zapata Navarro, "Literatura y realidad: el cuento maravilloso", 47-56.

Carmen González Escudero, “El elemento “agua” en los poemas de la antología poética de Joaquín Benito de Lucas", 57-66.

\section{Aldaba, Revista del Centro Asociado a la UNED de Melilla, n¹3, 1989.}

José Megías Aznar, "Presentación”, 7-10.

Antonio González Bueno, “Algo más de doscientos años de preocupación por la naturaleza en Melilla y su tierra”, 11-28.

José Manuel Cabo Hernández, "Perspectivas medioambientales en Melilla”, 29-36.

Ángel Enrique Salvo Tierra, "Historia de la flora mediterránea”, 37-44.

Antonio Manuel Escámez Pastrana, "Las Islas Chafarinas y su problemática medio ambiental”, 45-70.

Jaime Rodríguez Martínez, “Oceanografía del Mar de Alborán”, 71-88.

Antonio Manuel Escámez Pastrana, “Los helechos: elementos esenciales en la conservación de nuestra flora”, 79-118.

\section{Aldaba, Revista del Centro Asociado a la UNED de Melilla, nº14, 1989.}

Joaquín Summers Gámez, profesor titular de Física, UNED, "Presentación. Seminario Ciencia y Sociedad", 7-8.

Sebastián Dormido y J.M. de la Cruz, "Inteligencia Artificial: pasado presente y futuro", 9-22. José Luis Tellería, “Importancia de España en la conservación de la Naturaleza”, 23-30.

Manuel Espinosa, "Impacto de la Biotecnología en la sociedad: presente y futuro", 31-38.

Joaquín Summers Gámez, "La ciencia en la sociedad: Inteligibilidad e influencia”, 39-52.

Aldaba, Revista del Centro Asociado a la UNED de Melilla, $\mathbf{n}^{\circ} 15,1990$. Coordinador de este número Vicente Moga Romero.

I Introducción

Vicente Moga Romero, coordinador del monográfico, “Aldaba de Melilla: La historia interesada”, 9-12.

II Estudios

Antonio Bravo Nieto, "La ocupación de Melilla en 1497 y las relaciones entre los Reyes Católicos y el Duque de Medina Sidonia”, 15-37. 
Salvador Gallego Aranda, "La construcción del edificio de la Cámara de Comercio, Industria y Navegación de Melilla: Enrique Nieto”, 39-48.

Paloma Moratinos Bernardi, "Vidrieras de Adolph Seiler en Melilla: Estudio iconográfico" 49-64.

Adoración Perpén Rueda y Vicente Moga Romero, “Carlota O’Neill: una mujer en la guerra de España”, 65-82.

Ali Mohamed Laarbi, “Contribución para la comprensión del Áfricanismo español”, 83-88.

Jesús Salafranca Ortega, “Costumbres religiosas de los judíos melillenses”, 89-111.

III Monográfico: Campaña del Rif(1909)

Juan Díez Sánchez, “Melilla 1909: Álbum gráfico” 115-170.

Francisco Saro Gandarillas, “Aproximación a una bibliografía crítica sobre la "Campaña del Rif" de 1909", 171-199.

IV Reseñas

Antonio Bravo Nieto, "Melilla en el Siglo XVI a través de sus fortificaciones, por Antonio Bravo Nieto y Jesús Sáez Cazorla”, 199-200.

Adoración Perpén Rueda, "Melilla la codiciada y los buscadores del pan: Novela por Juan Berenguer Rodríguez”, 200-201.

Vicente Moga Romero, “Catálogo sistemático (CDU) de la sección de Melilla de la Biblioteca Pública Municipal (año 1988), por Vicente Moga Romero”, 201- 202.

José Megías Aznar, “El libro de Tamar, por Almudena Guzmán”, 203-204.

Aldaba, Revista del Centro Asociado a la UNED de Melilla, n¹6, 1991, dedicado a: Monográfico Melilla. Coordinador de este número Vicente Moga Romero.

I Introducción

Vicente Moga Romero, coordinador, “Introducción”, 9.

II Estudios

Paloma Moratinos Bernardi, “Joyería Púnica en Melilla: Los pendientes de la necrópolis del Cerro de San Lorenzo”, 13-26.

Mustafa Akalay Naser, "Gaudí elTangerino, Un proyecto inédito: Las misiones Franciscanas de Marruecos”, 27-36.

Salvador Gallego Aranda, "La biblioteca de la Cámara Oficial de Comercio, Industria y Navegación de Melilla”, 37-48.

José Luis Fernández de la Torre, "Notas para un análisis de la poesía de Miguel Fernández”, 49-60. 
II Apuntes

Manuel Soria Pérez, "Desertización en África”, 61-66.

Ali Mohamed Laarbi, "La lengua heredada y el uso que se hace de ella”, 67-72.

Ángel Pérez González, “Apuntes sobre el nacionalismo en el Rif”, 73-76.

José Javier García Salama, “Filatelia e historia: la campaña de los sellos (1893-1894)”, 77-92.

IV Monográfico: IKelaia

Lucas Calderón y Adela Ana Ponce Gómez, "Itinerario místico-mágico por Ikelaia: Morabos, leyendas y tradiciones populares”, 93-108.

$V$ Reseñas

Claudio Barrio Fernández de Luco, "Enrique Gozalves Cravioto. La ciudad antigua de Rusadir, aportaciones a la historia de Melilla en la antigüedad”, 109-110.

Daniel Uchen, “Antonio Bravo Nieto y Vicente Moga Romero. Melilla, imágenes de su historia: álbum de cromos”, 110-111.

RafaelVélez, "Vicente Moga Romero, Julia Rodríguez Picazo, Amelia Reyes López. Historia ilustrada de Melilla: Las edades históricas de una ciudad mediterránea”, 111-112.

Vicente Moga Romero, "Francisco Carcaño Mas. Melilla. Rifeñerías. Las plazas menores de África", 112- 115.

Pablo García Baena, “Arcadio López-Casanova. Razón de iniquidad”, 115-117.

Aldaba, Revista del Centro Asociado a la UNED de Melilla, $\mathbf{n}^{\circ}$ 17, 1991, dedicado a: Facsímil no 1, El Contagio de El Peñón de Vélez de la Gomera 1744. Editor de este número Vicente Moga Romero.

Vicente Moga Romero, "El Peñón de Vélez de la Gomera en 1743: La ciudadela y la peste negra”, 11-28.

Thomas Exarch, Juan de Figueroa y Joseph Serrano, “El contagio de el peñón que acredita los famosos tropheos de la facultad médica: individual descripción de la constitución pestilente que padeció aquella plaza el año 1743. Edición facsímil de la publicación original impresa en Málaga en 1744 por Thomas Exarch, Juan de Figueroa y Joseph Serrano”, 34-164.

“Álbum fotográfico del Peñón de Vélez de la Gomera”, 168-181.

\section{Aldaba, Revista del Centro Asociado a la UNED de Melilla, nº18, 1992.}

Blas Jesús Imbroda Ortiz, profesor-tutor de Derecho Penal, UNED Melilla, "Introducción”, 7-8.

Manuel Rodríguez López, Presidente de la Audiencia Provincial de Málaga, "La prisión provisional en la doctrina del tribunal Constitucional”, 9-30. 
José María Navarrete Urieta, Catedrático de Derecho Penal, “El nacimiento de la idea de culpabilidad", 31-42.

Enrique Ruiz Vadillo, presidente de la sala de lo Penal del Tribunal Supremo, vocal permanente de la Comisión General de Codificación y profesor de Universidad, "El derecho penal en la encrucijada del año 2000”, 43-64.

Blas Jesús Imbroda Ortiz, profesor-tutor de Derecho Penal, UNED Melilla, abogado, "El delito de impago de prestaciones por separación, divorcio o nulidad de matrimonio", 65-74.

Aldaba, Revista del Centro Asociado a la UNED de Melilla, nº19, 1992, dedicado a: Monográfico sobre la cultura tamazight:Amazigh-Tamazight, Debate Abierto. Editor de este número Vicente Moga Romero.

Vicente Moga Romero, “La identidad Tamazight: Debate abierto”, 9-14.

Rachid Ahmed Raha, “La cultura Tamazight: un tabú incomprensible”, 15-27.

Mohamed Chtatou, Said Jilali, Cadi Kaddour, "La lengua tamazight: presente y futuro", 29-38.

Ahmed Boukous, "Notas en torno a la problemática actual de la lengua Tamazight”, 39-43.

Naimia Moufra, “Datos de gramática contrastiva rifeño-española”, 45-74.

Mimunt Chaloukh, "El diccionario español-rifeño de Esteban Ibáñez: sus aportaciones a la lexicografía rifeña”, 75-89.

José Ignacio Valverde Martín, Halifa Kaddur Mohamed, Yamila Mohamed Maanan, "Una orientación propedéutica al amásigt hablado en Melilla”, 91-115.

Abdeluahab Hammouti, "La familia rifeña y el espacio”, 117-124.

El - Hassan Doudoh, “La mujer rifeña: un ejercicio de la evolución de la sociedad bereber”, 125-131.

David M. Hart, “Tradición, continuidad y modernidad en el derecho consuetudinario islámico: ejemplos del marruecos bereber y de las agencias tribales Pujtunes de Pakistan”, 133-150.

TassaditYacine, “Cultura y Sociedad: el ejemplo de Kabilia”, 151-163.

Mimun Ahmed Aziza, “Contribución al estudio de la emigración rifeña a Argelia 18321856”, 165-181.

María Rosa de Madariaga, "Melilla y la fiebre minera en el primer cuarto del siglo XX", 183-202.

Hussein Bouzalmate, “Amazigh 92: por la creación del centro de estudios Amazigh”, 203-211. 
Aldaba, Revista del Centro Asociado a la UNED de Melilla, ${ }^{\circ} 20,1992$, dedicado a: El mundo después de la guerra. Editor de este número Ramón Cotarelo.

Ramón Cotarelo, "Presentación”, 9-11.

Ramón Cotarelo, “Consideraciones sobre el fin de la bipolaridad”, 13-34.

Manuel Pastor, "Del finalismo comunista al fin del comunismo", 35-44.

Andrés de Blas Guerrero, "Democracia y nacionalismo. Unas difíciles relaciones", 45-58.

Juan Montabes Pereira, "La política y el Islam en el mundo árabe tras la guerra del Golfo", 59-76.

Ramón Cotarelo, "Sobre la política exterior de España”, 77-95.

Aldaba, Revista del Centro Asociado a la UNED de Melilla, no 21 I-1, junio de 1993, dedicado a: Estudios sobre la presencia española en el norte de África.

José Luis Fernández de la Torre, “Notas para una Introducción”, 9.

Juan Alfredo Bellón Cazabán (Universidad de Granada),”Los hermanos Machado y el Norte de África”, 11-26.

José Payá Bernabé (Casa-Museo Azorín, Obra Social de la CAM en Monóvar),"El problema de España en África según Azorín”, 27-36.

Pedro Galera Andreu (Universidad de Granada),’Osmosis cultural en la frontera. Arte en la frontera Nazarí”, 37-49.

Juan Díez Sánchez (Asociación de Estudios Melillenses), "Notas sobre la cartofilia melillense: Diego Mullor, caricaturista", 51-77.

Rafael Gutiérrez Cruz (Universidad de Málaga), "Melilla tras la conquista: documentos para su estudio”, 81-115.

Miguel Avilés Fernández (Catedrático de Historia Moderna de la UNED Madrid), ’Cisneros y el Norte de África”, 119-136.

María Palacios Alcalde (Profesora de Historia Moderna, UNED Madrid), "El mundo islámico visto por el mercader flamenco Joacques de Coutre”, 137-144.

Houssein Bouzalmate (Universidad Complutense, Madrid), "Marruecos en el pensamiento de Marcelino Domingo”, 145-160.

Rachid Ahmed Raha (Universidad Complutense, Madrid), “El "Dahir bereber” contra los bereberes", 161-166.

Marion Reder Gadow (Profesora titular de Historia Moderna, Universidad de Málaga),"El personal militar de la guarnición de Melilla y sus relaciones con el obispado de Málaga", 167-223.

María Dolores Torreblanca Roldán (Universidad de Málaga), "Malagueños cautivos en el norte de África (Siglo XVIII)”, 227-252. 
Juan Miguel Muñoz Corbalán (Profesor Universitat Autónoma de Barcelona), "Estrategia de la corona española para conservación de los presidios menores Africanos durante el Siglo XVIII", 253-294.

\section{Aldaba, Revista del Centro Asociado a la UNED de Melilla, $\mathbf{n}^{\circ} 22$ I-2, junio de 1993, dedicado a: Estudios sobre la presencia española en el norte de África.}

María Isabel Pérez de Colosía Rodríguez (Coordinadora del área de Historia Moderna, Universidad de Málaga), "Málaga y Melilla durante la transición de los austrias a los borbones", 9-33.

Fernando R. de la Flor (Universidad de Salamanca),"1732-1791, la ilustración y la crisis del modelo defensivo español en el Norte de África”, 35-63.

Manuel Álvarez Vázquez (Universidad de Málaga), "Martín de Bocanegra: un interrogante sobre la participación gibraltareña en la conquista de Melilla (1497)”, 65-96.

Francisco Saro Gandarillas (Historiador), "Los orígenes de la Campaña del Rif 1909”, 97-109.

Santiago Domínguez LLosá y María de los Ángeles Rival Ahuir (Asociación de Estudios Melillenses),"La junta local de deslindes y amojonamientos de Melilla (1866 - 1900)”, 131-133.

Ana María Vera Delgado (Archivo-Biblioteca-Hemeroteca de Málaga),"La imagen norteafricana según el archivo municipal de Málaga (originales y provisiones de los Reyes Católicos y Carlos I)”, 135-165.

Carlos Posac Mon (Historiador),"Proceso inquisitorial de Miguel Rubín de Celis, oficial de la guarnición de Melilla (1770)", 167-183.

José Luis Blanco López (Asociación de Estudios Melillenses),"Estudio y documentación de los capuchinos en Melilla y Vélez de la Gomera”, 185-204.

Luisa Auñón Manzanares (Archivo Central. Ministerio Relaciones con las Cortes y de la Secretaría del Gobierno). "Fuentes documentales para el estudio de la historia del Norte de África existentes en el archivo de la presidencia del Gobierno”, 205-227.

José Manuel González Sánchez (Archivo Histórico Nacional), "Fuentes documentales existentes en el Archivo Histórico Nacional para la historia del Norte de África con especial referencia a Melilla", 229-247.

Hans-Ludwig Dankwardt (Archivo Central del Ministerio de Relaciones con las Cortes y la Secretaría de Gobierno), "Los sefarditas en el Norte de África”, 249-254.

Ignacio Ruiz Alcaín (Director del Archivo Central del Ministerio de Relaciones con las Cortes y de la Secretaría del Gobierno), "Fuentes de la presidencia del Gobierno para la historia de la presencia española en África del Norte custodiadas en el Archivo Central de la Administración del Estado en Alcalá de Henares”, 255-291. 
Ali Mohamed Laarbi (Investigador),”El Rif y el protectorado español”, 293-303.

Jesús F. Salafranca Ortega (Historiador),"El concepto geopolítico de las fronteras de su católica majestad en Berbería”, 305-321.

Aldaba, Revista del Centro Asociado a la UNED de Melilla, no 23, abril de 1994, dedicado a: Miguel Fernández [In Memoriam].

José Luis Fernández de la Torre, "Introducción”, 9-11.

Manuel Cáceres Sánchez (Universidad de Granada), “A propósito de las "sombras” que pueblan la poesía de miguel Fernández: "El muchacho del chaleco rojo”, 13-22.

Antonio Chicharro Chamorro (Universidad de Granada), “Miguel Fernández: crítico de Gabriel Celaya”, 23-34.

José Lupiáñez, “Miguel Fernández: Los territorios espirituales”, 35-46.

Sultana Wahnón (Universidad de Granada), "Credo de libertad. La primera poética de Miguel Fernández”, 47-80.

Antonio Domínguez Rey, “Los ciclos poéticos de Miguel Fernández”, 81-94.

Emilio Miró (Universidad Complutense), “Cultura y vida: la poesía de Miguel Fernández”, 95-102.

Francisco Rincón Ríos, "El ars poética de Miguel Fernández (Evocación enmodulema)”, 103-116.

Arcadio López-Casanova (Universidad de Valencia), "Miguel Fernández, una poética de la revelación”, 117-127.

María del Pilar Palomo, "La recreación de la materia”, 129-139.

José Teruel (Universidad de Nueva York en España), "Retórica de la ceguera: una poética para Miguel Fernández", 141-153.

José Luis Fernández de la Torre, “Un inédito de Miguel Fernández: Solitudine”, 155-174.

Aldaba, Revista del Centro Asociado a la UNED de Melilla, no 24, junio de 1995, dedicado a: Jornadas sobre práctica de procesal. Análisis actual y nuevas orientaciones.

Carlos Granados Pérez (Fiscal General del Estado), "Principios del proceso penal: nuevas perspectivas", 11-24.

Enrique Ruiz Vadillo (Presidente de la Sala Penal del Tribunal Supremo y del Instituto Europeo de España. Profesor Universidad). "Los principios del proceso penal”, 25-45.

Luis-Román Puerta Luis (Magistrado del Tribunal Supremo), "La prueba en el proceso penal”, 47-80. 
Ignacio Sierra Gil de la Cuesta (Vocal del Consejo General del Poder Judicial), "Principios del proceso civil”, 81-91.

Rafael Fernández Montalvo (Vocal del Consejo General del Poder Judicial),”Análisis actual y orientaciones futuras del proceso contencioso - administrativo", 93-117.

Aldaba, Revista del Centro Asociado a la UNED de Melilla, $\mathbf{n}^{\circ}$ 25, septiembre 1995, dedicado a: Estudios sobre la presencia española en el norte de África.

José Luis Fernández de la Torre, "Presentación”, 9-12.

Miguel Ángel de Bunes Ibarra (Centro de Estudios Históricos CSIC), "La presencia española en el Norte de África: las diversas justificaciones de las conquistas en el Magreb”, 1334.

María Pilar Castro Martos (Jefa de la Sección de Estado del Archivo Histórico Nacional), "Proyección de España en África: la documentación de la sección de Estado del Archivo Histórico Nacional”, 35-49.

Antonio Francisco González Reyes, "La esclavitud en los presidios Africanos durante el Siglo XVIII”, 51-59.

Francisco Mir Berlanga (Cronista Oficial de Melilla), 'Los archivos de Melilla la Vieja y su dispersión documental”, 61-67.

Marión Reder Gadow (Universidad de Málaga), “El comportamiento de la población de Melilla en la transición del XVII al XVIII”, 69-104.

Joaquín Rodríguez Puget, "El agua de Melilla: aljibes y pozos en los tres primeros recintos fortificados", 105-123.

Luis Sarompas Hernández, “Aproximación a las relaciones entre álaga y Melilla a través de los estudios malagueños (1497-1800)”, 125-134.

Ismet Terki-Hassaine (Universidad de Orán, Argelia), "Problemática cuestión de las posesiones españolas en la Argelia del Siglo XVIII: caso de Orán y Mazalquivir”, 135-158.

José Luis La Torre Merino, María del Carmen Valverde Zabaleta y otros (Archivo General de la Administración de Alcalá de Henares), "Fondos documentales para el estudio de la presencia española en el continente africano conservados en el archivo central de la administración”, 159-206.

Ana María Vera Delgado (Directora del Archivo Municipal de Málaga), "Un ejemplo de dispersión documental para la historia norteafricana. El archivo-biblioteca municipal de Málaga”, 207-214. 
Aldaba, Revista del Centro Asociado a la UNED de Melilla, $\mathrm{n}^{\circ}$ 26, septiembre de 1995, dedicado a: Estudios sobre la presencia española en el norte de África.

José Luis Fernández de la Torre, "Presentación”, 9-11.

Encarnación Albasanz Mata y Luisa Auñón Manzanares (Archivo Central del Ministerio de Relaciones con las Cortes y de la Secretaría del Gobierno), "El problema de África durante la dictadura de Primo de Rivera a través de las actas de los Consejos de Ministros de los años 1925 a 1930”, 13-89.

Juan Aranda Doncel (Doctor en Historia), "La administración borbónica y el sostenimiento de la plaza de Ceuta en el Siglo XVIII: el reglamento de 1745”, 91-111.

Miguel Ángel de Bunes Ibarra (Centro de Estudios Históricos CSIC), "El marco ideológico de la expansión española por el Norte de África”, 113-134.

Ricardo Domínguez Llosa, "La Guelaia como es: Hipótesis para su comprobación. (La construcción de espacios en una región de frontera)”, 135-146.

Isabel Palomera Parra y Jesús Gaite Pastor, "Fuentes para la historia de Ceuta y Melilla en la sección de fondos contemporáneos del Archivo Histórico Nacional”, 147-156.

José Luis Gómez Barceló (Archivo Municipal de Ceuta), "Melilla, origen y destino en el archivo de la Santa y Real Casa de misericordia de Ceuta”, 177-193.

Carlos González Cravioto, "Introducción al análisis comparativo de las fortificaciones de Ceuta y Melilla en el Siglo XVI”, 195-207.

Carlos Posac Mon, "Noticias sobre Melilla en la prensa madrileña durante elTrienio Constitucional (1820 - 1823)”, 209-239.

Marión Reder Gadow (Universidad de Málaga), "El controvertido gobierno de Don Juan Jerónimo Ungo de Velasco en la plaza de Melilla”, 241-284.

Juan Torrejón Chaves (Universidad de Cádiz), “Gobierno y economía de Argel en el Siglo XVII: la información secreta al Rey de España”, 285-307.

Jorge Vera Aparici (Doctor en Bellas Artes), "El castillo de Santa Cruz. Paradigma de la arquitectura militar española en Orán”, 309-343.

Juan Bautista Vilar (Universidad de Murcia) y Mikel de Epalza (Universidad de Alicante), "Un ejemplo de conjunto histórico arquitectónico en liquidación. El sistema de fortificaciones españolas en Orán (1504 - 1891)”, 345-366.

María Isabel Pérez de Colosía Rodríguez (Universidad de Málaga), "El norte de África, destino de los moriscos perseguidos por la Inquisición”, 367-379. 


\section{Aldaba, Revista del Centro Asociado a la UNED de Melilla, no 27, junio 1996, dedi- cado a: Construir desde la diversidad.}

"Introducción", 9-10.

José Luis López Belmonte y Sebastián Sánchez Fernández (Comisión organizadora Construir desde la Diversidad), "Contra el racismo y la xenofobia: construir desde la diversidad", $11-13$.

Francisco Imbernón Muñoz (Catedrático del Departamento de Didáctica y Organización Educativa de la Universidad de Barcelona), "De la individualización a la diversidad. Cambiar las personas y los contextos”, 15-27.

Sebastián Sánchez Fernández (Catedrático de Didáctica y Organización Escolar de la Escuela de Magisterio de Melilla), "La educación intercultural y su tratamiento en los proyectos de centro", 29-55.

José Antonio Antón y Anna Ros (Miembros de ENTREPUEBLOS, Valencia), "Racismo, interculturalismo y sistema escolar”, 57-69.

José Domínguez (Maestro de Almería que ha trabajado con minorías étnicas y emigrantes), "Por una educación intercultural. Emigrantes", 71-73.

Ulf Fredriksson (Coordinador del Departamento de Educación de la Internacional de la Educación, Bruselas), "Educación intercultural: emigración y minorías nacionales en organismos internacionales”, 75-92.

José M. Cabo (Catedrático de Magisterio de Melilla), Ángel Gutiérrez, Carmen Sol Moreno, Cristina Montes y Adela Tormo (Maestros), "Intercultura e igualdad de oportunidades", 93-103. Juan GrandaVera (Profesor de Magisterio Melilla), Said El-Ouariachi Anan y Rafael Domínguez Saura (Maestros), “Juegos populares de la cultura bereber (Tamazight)”, 105-113.

Rachid Raha Ahmed (Investigador en Antropología Amazight-Bereber, presidente de la asociación de Cultura Tamazight en España), “Por qué enseñar el Tamazight en España?”, 115-120.

\section{Aldaba, Revista del Centro Asociado a la UNED de Melilla, no 28, octubre 1996, dedicado a: Actas del I Congreso Internacional de Hispanistas.}

Jesús F. Salafranca Ortega (Director del Congreso), “Presentación”, 11-12.

Miguel Ángel Rubio Gandía (Universidad de Granada. España), "El Magreb y España: el desarrollo humano", 13-38.

Javier Martínez Alcázar (Embajada de España en Lagos, Nigeria), "Convenio entre la federación de Nigeria y la provincia española del Golfo de Guinea”, 39-52.

Anne-Marie Wohrer (C.I.E.E.I.T. París, Francia), "Reconocimiento o negociación por los españoles del Siglo XVI de un sistema de escritura indígena en el México central”, 53-66. 
Lioudmila Rabdano (Instituto de Lenguas Extranjeras de lrkutsk, Siberia, Rusia), “El español en Rusia, Problemas linguo-didácticos”, 67-74.

Amalia Roales-Nieto y Azañón (Universidad Complutense de Madrid, España), "La música militar en tiempos del general San Martín”, 75-86.

José Manuel Gómez-Tabanera (Universidad de Oviedo, España),"Realidades e interrogantes de un hispanista ante la llamada dama de Elche”, 87-108.

Ana María Fernández García (Universidad de Oviedo, España), "Interacciones del arte español e iberoamericano”, 109-120.

Ana Rita Valero (Universidad Nacional Autónoma de México, México D.F, México), “Un litigio indio en el Siglo XVI. El Códice Cozcatzín”, 121-136.

Luz María Mohar Betancourt (Centro de Investigaciones y Estudios Superiores en Antropología Social, México D.F., México), “Coatlichan. Líneas y colores en el Acolbuacán”, 137-162.

Jesús Monjaras-Ruiz (Instituto Nacional de Antropología e Historia, México D.F., México),"Algunos aspectos comparativos de las empresas evangelizadoras Católica y Protestante en América según Ortega y Medina”, 163-172.

María Teresa Ruiz de la Parte (Federación de Centros Castellanos, Madrid, España), "Vinculación histórica entre Castilla y América a lo largo de cinco siglos", 173-182.

Ada Lattuca (Universidad Nacional de Rosario, Argentina), "Acerca de lo hispánico en la Universidad Argentina”, 183-192.

Isidro Sepúlveda Muñoz (Universidad Nacional de Educación a Distancia, Madrid, España),"La comunidad cultural iberoamericana y el nacionalismo español”, 193-214.

Cristina Bredt-Kriszat (Universidad de Hamburgo, Alemania), "Un texto religioso de mediados del Siglo XVI en Guatemala a “La teología Indórum” de Fray Domingo deVico”, 215-234.

Agueda Rivera Garrido (Escuela de Estudios Hispano-Americanos, Sevilla, España),'La situación económica de la audiencia de Quito durante la segunda mitad del Siglo XVIII”, 235-268.

Rosario Aguayo (Colegio Santa Rosalía, Málaga, España), "Hispanidad en torno a la conquista de México", 249-268.

María Eliza Linhares Borges (Universidad Federal de Mina Gerais, Belo Horizonte, Brasil), “A regulaçao de cidadania em Ibero-América: dilemas da moderniçao", 269-284.

María Isabel Jiménez Morales (Universidad de Málaga, España),'Los españoles pintados por sí mismos (1843 - 1844): una mirada masculina al universo femenino”, 285-300.

Octavio Soares Dulci (Universidade Federal de Minas Gerais, Belo Horizonte, Brasil), "Perspectivas de sociología brasileira: Afirmaçao en superraçao de herença ibérica”, 301-312.

Jeanette M. Brock (Universidad de Glasgow, Escocia, Gran Bretaña), "The impact of emigrant remittances on Spanish and Scottish society in the second half of the Twentieth Century", 313-326. 
Amparo Quiles Faz (Universidad de Málaga, España), "Las hermandades de los negros y del pecado mortal: dos manifestaciones religiosas en la Málaga de los siglos XVIY XVII”, 327-348.

Alfredo González (Buró de Educación de Chicago, Illinois, Estados Unidos),”La evolución del castellano en los Estados Unidos”, 349-364

Osvaldo Picardo (Universidad Nacional del Mar del Plata, Buenos Aires, Argentina), "Construcción de la realidad poética: el poeta como personaje y la realidad como ficción: Luis A. de Villena”, 365-380.

Marta Beatriz Ferrari (Universidad Nacional de Mar del Plata, Buenos Aires, Argentina), "Referencia y auto referencia: la práctica meta poética en la escritura de Guillermo Carnero", 381-388.

Brigada Pastor Pastor (Universidad de Surrey, Londres, Inglaterra), "Simbolismo autobiográfico en la novela “SAB” de Gertrudis Gómez de Avellaneda”, 389-404.

Mark Aldrich (Dickinson College, Carlisle, Pensilvania, Estados Unidos),'La poética del futuro de Luis Cernuda y su reflejo en Francisco Brines”, 405-420.

Annunziata O. Campa (Universidad de Pisa, Italia), “Axiología del lenguaje en la escritura femenina: "En cualquier lugar" de Marta Traba", 421-436.

Mercedes Cobos (Universidad de Sevilla, España),'La partida de bautismo y otros datos inéditos para la biografía del poeta áureo sevillano Hernando de Soria Galvarro”, 437-458.

Pedro Pascual Martínez (Universidad Politécnica de Madrid, España), "Los goliardos desaparecieron hace siete siglos", 459-474.

Susana Guerrero Salazar (Universidad de Málaga, España), “Los poetas-soldados y el trasvase cultural en el renacimiento", 475-498.

Luigi Monga (Universidad de Vanderbilt, Nashville, Tennessee, Estados Unidos), “El viaje a Italia en las obras de Cervantes: ¿Ficción o autobiografía?”, 499-510.

Celia Vega Martín (Universidad de Málaga, España), “La figura de Miguel Delibes en la cultura europea finisecular: proyección y análisis”, 511-528.

María Jesús Perea Vázquez (Universidad de Málaga, España), "Hispanoamérica y la Guerra Civil Española vista a través de sus poetas: César Vallejo y Pablo Neruda”, 529-542.

Aldaba, Revista del Centro Asociado a la UNED de Melilla, no 29, abril 2003, dedicado a: V Curso El aprendizaje del castellano en el alumnado de habla tamazhigt. Coordinadores de este número José Luis López Belmonte y Ana Isabel Lara Castaño.

José Luis López Belmonte y Ana Isabel Lara Castaño (Director y coordinadora del curso), "Presentación", 9-11.

Sebastián Sánchez Fernández (Catedrático de Didáctica y Organización Escolar), "Interculturalidad, Inmigración y Educación”, 13-33.

Juan Francisco Mayoral del Amo (Educador social), "El contexto de Melilla”, 33-56. 
Jorge Cano Moreno (Jefe de estudios del IES Juan Antonio Fernández Pérez), “Atención educativa a las necesidades especiales relacionadas con el contexto sociocultural”, 57-70.

Gloria Rojas Ruiz (Profesora de la Facultad de Ciencias de la Educación y Humanidades, Universidad de Granada, Campus de Melilla), "Estrategias para fomentar actitudes interculturales positivas en el aula", 71-87.

Jalifa HassanYahia (Responsable del Seminario Permanente de Lengua y Cultura Tamazight), “Caminando en la didáctica de la lengua rifeña”, 89-125.

María José Molina García (Profesora de la Facultad de Educación y Humanidades de Melilla, Universidad de Granada, Campus de Melilla), "Fundamentos teóricos de la educación bilingüe”, 127-138.

Ana María Rico Martín (Profesora de la Facultad de Educación y Humanidades de Melilla, Universidad de Granada, Campus de Melilla), "Metodología de la enseñanza del español como segunda lengua”, 139-152.

María Soledad Martínez Gámez (Maestra de Educación Infantil en el CEIP Pintor Eduardo Morillas), “Aprendizaje de la lectoescritura en un contexto intercultural en la educación infantil”, 153-167.

Concepción Hernández Noguera (Maestra de Educación Primaría en el CEIP León Solá), “Educación primaria. Estrategias de intervención en contextos multiculturales”, 169-188.

María Ángeles Sánchez Suárez (Jefa de Estudios del Centro de Educación de Personas Adultas, Melilla), "Reflexiones acerca de la enseñanza del español como lengua de segunda adquisición a personas adultas hablantes de Tamazight”, 189-235.

Tomás Calvo Buezas (Catedrático de Antropología Social, UCM, Director del Centro de Estudios sobre Migraciones y Racismo - CEMIRA-), "Interculturalidad y Educación”, 237-252.

\section{Aldaba, Revista del Centro Asociado a la UNED de Melilla, n 30, noviembre 1998, dedicado a: Melilla y su entorno en la antigüedad.}

Pilar Fernández Uriel (Directora del simposium), "Presentación. Simposium: Melilla y su entorno en la antigüedad”, 9-11.

Federico Lara Peinado (Universidad Complutense de Madrid), "Melilla: entre Oriente y Occidente”, 13-34.

Fernando López Pardo (Universidad Complutense de Madrid),"Rusadir: de la memoria literaria a la realidad histórica de la expansión Fenicio - Púnica en Occidente", 35-52.

Pilar Fernández Uriel (Departamento de Prehistoria e Historia Antigua, UNED), "Melilla en el comercio del Mediterráneo: miel, sal y púrpura”, 53-88.

Ana María Vázquez Hoys (Departamento de Prehistoria e Historia Antigua, UNED), "En las manos de Astarté, la abrasadora”, 89-140. 
Víctor M. Guerrero Ayuso (Departamento de Ciencias Históricas, Universidad de las Islas Baleares), “La navegación en el mundo antiguo. Mercantes fenicios y cartagineses”, 141-192. Claudio Barrio Fernández de Luco, "La numismática y Melilla”, 193-230.

Santiago Montero Herrero, "La conquista de Mauritania y el milagro de la lluvia del año 43 D.C.", 231-240.

José María Álvarez Martínez, “Algunas observaciones sobre la influencia africana en el mosaico hispanorromano", 241-260.

Pilar Gómez Serrano (Profesora Titular de Arqueología, Universidad Complutense de Madrid), “África romana”, 261-276.

Juan Zozaya, “En torno al mundo islámico de Melilla”, 277-303.

Aldaba, Revista del Centro Asociado a la UNED de Melilla, $\mathbf{n}^{\circ}$ 31, octubre 2001, dedicado a: Actas del II Coloquio Internacional de Estudios sobre África y Asia.

Javier Martínez Alcázar, "La crisis de marzo de 1969 en Guinea Ecuatorial”, 9-24.

Francisco J. Palacios Romero (Universidad de Zaragoza, España), "Razón jurídica y razón política en el proceso de descolonización del Sáhara Occidental”, 25-50.

María Dolores Algora Weber (Universidad San Pablo CEU, Madrid, España), "El mundo árabe al inicio de la guerra fría. ¿Descolonización o colonización?”, 51-70.

Genoveva González Fanjul, "El fracaso de España en la primera ocupación de los territorios del Golfo de Guinea”, 71-84.

Manuel Burgos Madroñero (Universidad de Málaga, España), “Crónicas portuguesas de la Guerra Civil de España. Los informes del Vicecónsul portugués en Fernando Poo (14 de agosto - 31 de octubre de 1936)", 85-106.

María Jesús Merinero Martín (Universidad de Extremadura, España), "Irán 2000: estrategias electorales y mecanismos de control", 107-124.

Marisa Vannini de Gerulewicz (Universidad Central deVenezuela), "Las islas de CaboVerde y la costa occidental de África en la ruta de los primeros viajes a América”, 125-148.

Oñez Monjas Hernández (Universidad de Málaga), "La voz y la mirada de la mujer musulmana”, 149-166.

Amelia Roales-Nieto, "La lengua y la cultura castellanas en Corea”, 167-180.

María Josefa Parejo Delgado (IES. Vicente Aleixandre, Sevilla, España), "El paisaje, la guerra y el nacionalismo marroquí en las crónicas de José Mª Sevillano (1926-1926)”, 181-202.

Inmaculada Delgado Cobos (Universidad Complutense, Madrid, España), "La incidencia filosófica árabe-española”, 203-212.

Epifanio Borreguero García (Archivo General Militar, Segovia, España), “Asuntos sobre África en el Archivo General Militar de Segovia”,213-232. 
María Ángeles Santiago y Miras,”Un nuevo país ¿y ahora qué? La integración de los emigrantes afroasiáticos", 233-238.

Inmaculada Berlanga Fernández,’Temática folclórica en la literatura asiática (Oriente Extremo). Relación con los mitos griegos”, 239-252.

Ana Bernard Da Costa (Bolseira da Fundaçao da Ciencia e Técnologia, Universidad Técnica, Lisboa, Portugal), "Familias na periferia de Maputo (Moçambique). Análise de relaçóes e comportamentos socio-económicos em contexto de mudança”, 253-268.

Carmen A. Martínez Albarracín (UNED Úbeda, España), "La situación de los palestinos refugiados en el Líbano a finales del Siglo XX”, 269-282.

$\mathrm{M}^{\mathrm{a}}$ Ángeles Morán Rodríguez y Ángel Navarro Madrid (Universidad Complutense de Madrid, España), "Las migraciones interiores y exteriores en el Magreb: repercusiones demográficas socioeconómicas y medio ambientales”, 283-298.

Ilde García Felipe (Asociación Internacional de Juristas para el Sáhara Occidental

-JAJUWS-), “Sáhara Occidental - Timor Oriental. ¿Gemelos hacia la paz?”, 299-312.

SolTorres Chamorro (Universidad Católica de San Antonio, Murcia, España), "Visibilización de la emigración magrebí en el espacio urbano”, 315-330.

M ${ }^{a}$ Teresa Miret García (Universidad Católica de Murcia, España), Álvaro Bernalte Benazet (Universidad de Cádiz, España), Alexandre Bernalte y Nuria López, "Antropología de la salud: Patocenosis comparadas ... Algo se nos escapa”, 331-340.

Abel Albeti Mas (Universidad Autónoma de Barcelona, España), "La ordenación del territorio en el protectorado español en Marruecos”, 341-358.

Silvia Rico Botella (Universidad Católica de San Antonio, Murcia), "Sociomorfología en la ciudad islámica tradicional”, 359-370.

Juan M. Zarandona Fernández (Universidad de Valladolid, España), “Hacia una redefinición de las historiográficas literarias nacionales Africanas. Los ejemplos de Sudáfrica y Guinea Ecuatorial”, 371-384.

José Luis Villanova Valero (Universidad de Gerona, España), "La academia de interventores del protectorado de España en Marruecos”, 385-404.

$\mathrm{M}^{\mathrm{a}}$ del Águila Boge Pineda (Asociación de Prensa Argentina), "La trinidad monoteísta: Judaísmo, Cristianismo e Islamismo”, 405-410.

Aldaba, Revista del Centro Asociado a la UNED de Melilla, $\mathbf{n}^{\circ} 32,2004$, dedicado a: Bioética, Filosofía y Derecho. Coordinadora del número Ana María marcos del Cano. Ana María Marcos del Cano (Directora del curso y coordinadora de la obra), "Presentación", 9-11.

Benito de Castro Cid (Catedrático de Filosofía del Derecho, UNED), "Biotecnología y derechos humanos: ¿Complementariedad o Conflicto?”, 13-30. 
Antonio- Enrique Pérez Luño (Catedrático de la Facultad de Derecho, Universidad de Sevilla), "Bioética e intimidad. La tutela de los datos personales biomédicos", 31-62.

Francesca Puigpelat Martí (Catedrática de Filosofía del Derecho, Universidad Autónoma de Barcelona),"Feminismo y las técnicas de reproducción asistida”, 63-80.

Jesús Ayllón Díaz (Profesor Asociado de Filosofía del Derecho, UNED), “Biociencia y jurisprudencia”, 81-105.

María Casado González (Directora del Centre de Recerca Observatori de Bioética i Dret, Directora del Máster de Bioética y Derecho, Profesora Titular de Teoría y Filosofía del Derecho Universidad de Barcelona, Miembro de la Comisión de Bioética de Cataluña, Presidenta de la Asociación de Bioética y Derecho), "Hacia la autonomía en sanidad”, 107-118.

Rafael Junquera de Estéfani (Profesor titular de Filosofía del Derecho, UNED), “El derecho y la bioética”, 119-137.

Andrés Ollero Tassara (Catedrático de Filosofía del Derecho, Universidad Rey Juan Carlos, Madrid), “La invisibilidad del otro. Eutanasis y dignidad humana”, 139-164.

Narciso Martínez Morán (Profesor titular de Filosofía del Derecho, UNED), "La dignidad humana en las investigaciones biomédicas", 165-205.

Ana María Marcos del Cano (Profesora Titular de Universidad de Filosofía del Derecho

de la Facultad de Derecho, UNED), “Cuidados paliativos y Eutanasia: Especial referencia a la legislación Belga”, 207-220.

Iñigo de Miguel Beriain (Becario de Investigación del Departamento de Filosofía del Derecho, UNED), “Terapias genéticas: un estudio ético - jurídico”, 221-249.

Marciano Vidal García (Catedrático de Teología Moral, Universidad Pontificia de Comillas, Madrid), "El uso terapéutico de células troncales humanas", 251-278.

José Delgado Pinto (Catedrático de Filosofía del Derecho, Universidad de Salamanca), "Ética comunicativa y Bioética”, 279-295.

Aldaba, Revista del Centro Asociado a la UNED de Melilla, $\mathbf{n}^{\circ} 33,2008$, dedicado a: Art Déco y arquitectura, imágenes de modernidad-Art Déco et architecture, images de modernité. Editor de este número Antonio Bravo Nieto.

José Megías Aznar (Secretario del Centro Asociado a la UNED en Melilla),”Introducción: Art Déco como patrimonio e identidad", 13-16.

Francisco Javier Pérez Roja (Universidad de Valencia, España), "La exposición internacional de artes decorativas e industriales modernas de París de 1925 y la crítica española” y "L'exposition internationale des arts décoratifs et industriels modernes de Paris en 1925 et la critique espagnole", 17-101.

Ezio Godoli (Universidad de Florencia, Italia), "Marcello Piacentini y el Art Déco en los cines italianos” y “Marcello Piacentini et l'Art Déco dans les cinemas italiens”, 103-142. 
Romeo Carabelli (Universidad de Tours, Francia), "L'art Déco en Italia: Etapas de valoración” y “L'Art Déco en Italie: des parcours de mise en valeur”, 143-184.

Vassilis Colonas (Universidad de Tesalia, Grecia), "La arquitectura y el Art Déco en Grecia entre el eclecticismo y el clacisismo moderno” y “L'architecture de l'Art Déco en Gréce. Entre éclecticisme et classicisme moderne”, 185-220.

Mercedes Volait (CNRS, Francia), “Un conjunto Art Déco en las afueras del Cairo: Heliopolis” et "Un ensemble urbain art déco en Egypte: Héliopolis, banlieue du Caire”, 221-254.

Boussad Aiche (Universidad Mouloud Mammeri, Tizzi Ouzou, Argelia), "El Art Déco y las premisas de la arquitectura moderna en Argel” y "L'Art Déco et les prémisses de l'architecture moderne à Alger", 255-286.

Antonio Bravo Nieto (UNED-Universidad de Málaga, España), "El Art Déco en Melilla: del zig-zag moderna a la estética de la máquina” y “L'Art Déco à Melilla: du Zig-Zag moderne à l'esthétique aérodynamique", 287-334.

Abderrahim Kassou (Casamemoire, Casablanca, Marruecos), "El Art-Déco en Casablanca” y “Art Déco à Casablanca”, 335-392.

Antonio Bravo Nieto (UNED-Universidad de Málaga), "La destrucción del Monumental Cinema y la defensa del patrimonio Art Déco" y "La destruction du cinema Monumental et la défense du patrimoine art déco”, 393-429.

Aldaba, Revista del Centro Asociado a la UNED de Melilla, $\mathbf{n}^{\circ} 34,2009$, dedicado a: Arquitectura militar y artillería en el Norte de África: de la fortificación islámica a los modelos abaluartados. Editor de este número Antonio Bravo Nieto.

José Megías Aznar, “Introducción”, 9-11.

Javier López Martín, “Artillería y fortificación en el contexto norteafricano”, 13-49.

Francisco Javier Bueno Soto, "Larache y La Mamora: dos fortificaciones españolas en tiempos de Felipe III", 51-96.

Samir Raoui, "Casbah de Mahdiya: une fortification espagnole au coeur de L'atlantique”, 97-143.

José Luis Gómez Barceló, “Ceuta, una ciudad fortificada”, 145-166.

Montaser Laoukili, "Los Basatin Saadianos de Fez. Aspectos de la arquitectura defensiva en Marruecos a finales del siglo XVI”, 167-188.

Antonio Bravo Nieto, "La alcazaba de Frajana, un modelo de fortificación islámica en el siglo XIX”, 189-215.

Metair Kouider, “Oran, une ville de fortifications”, 217-236. 
Aldaba, Revista del Centro Asociado a la UNED de Melilla, no 35, 2011, dedicado a: La socio-economía de Melilla en 2012: visiones proactivas desde la encrucijada actual. Coordinador del número Jesús García Ayala.

José Megías Aznar, "Presentación”, 9-11

Área: Melilla en el contexto regional

Virgilio González Fernández (Universidad de Granada), Tomás J. López-Guzmán (Universidad de Córdoba), "Política turística de un destino singular: Melilla (España)", 13-31.

Área: Melilla en el contexto nacional

Jesús A. García Ayala (Doctor en Ciencia Política y de la Administración por la Universidad de Granada, Licenciado en Ciencias Económicas y Empresariales por la Universidad Complutense de Madrid), "Bonificación de determinadas cuotas de la seguridad social en Melilla: evaluaciones y perspectivas”, 33-70.

Área: Melilla en el contexto comunitario

Jesús A. García Ayala (Doctor en Ciencia Política y de la Administración por la Universidad de Granada, Licenciado en Ciencias Económicas y Empresariales por la Universidad Complutense de Madrid, Director General de Fondos Europeos de la Ciudad Autónoma de Melilla), “Aplicación de las políticas de la Unión Europea en Melilla entre 1986 y 2008 : valoración de sus efectos y prospectiva sobre mejoras (I)”, 71-89.

Área: Melilla en el contexto norteafricano

José María López Bueno (Doctor en Economía y Relaciones Internacionales por la Universidad Autónoma de Madrid, M.B.A. por la Universidad de Denver, Licenciado en Ciencias Económicas y Empresariales por la UNED, Presidente de la Fundación para el Desarrollo Socioeconómico Hispano-Marroquí FHIMADES), “Melilla y sus relaciones con su entorno marroquí inmediato: teoría, práctica y oportunidades”, 91-107.

Jesús A. García Ayala (Doctor en Ciencia Política y de la Administración por la Universidad de Granada, Licenciado en Ciencias Económicas y Empresariales por la Universidad Complutense de Madrid), "Principales factores transversales de inseguridad económicosocial en Melilla con origenen el entorno norteafricano”, 109-138.

Jesús A. García Ayala (Doctor en Ciencia Política y de la Administración por la Universidad de Granada, Licenciado en Ciencias Económicas y Empresariales por la Universidad Complutense de Madrid), "Revolución de los jazmines en Túnez: posibles repercusiones en Melilla a través de Marruecos”, 139-162.

Marisa Escámez Pastrana (Diplomada en Educación Social, Diplomada en Trabajo Social, Máster Universitario Oficial en Problemas Sociales por la UNED), "Las menores extranjeras no acompañadas en Melilla: ¿menores o extranjeras?”, 163-174. 
Aldaba, Revista del Centro Asociado a la UNED de Melilla, no 36, 2012, dedicado a: Alimentos, calidad y seguridad alimentaria.

Pilar Fernández Hernando, "Presentación”, 11-12.

Alejandrina Gallego Picó (Departamento de Ciencias Analíticas, Facultad de Ciencias, UNED), “Características de los alimentos y control de calidad”, 13-34.

David González Gómez, Departamento de Ciencias Analíticas, Facultad de Ciencias, UNED, “Alimentos funcionales: propiedades saludables, análisis y distribución en alimentos", 35-50.

Rosa María Garcinuño Martínez (Departamento de Ciencias Analíticas, Facultad de Ciencias, UNED), "Contaminación de los alimentos durante los procesos de origen y almacenamiento", 51-64.

Pilar Fernández Hernando (Departamento de Ciencias Analíticas, Facultad de Ciencias, UNED), "Contaminación producida durante el procesado, preparación, transporte y limpieza de los alimentos", 65-78.

Consuelo Boticario Boticario (Departamento de Ciencias Analíticas, Facultad de Ciencias, UNED), "Nutrición y alimentación: mitos y realidades”, 79-88.

Hanif Escudero Uribe (Instituto Halal), "Halal, un concepto global”, 89-98.

Coty Aserin Farache (Casa Sefarad), "Las leyes dietéticas del judaísmo. Una dieta para el alma”, 99-103.

Aldaba, Revista del Centro Asociado a la UNED de Melilla, no 37, 2013, dedicado a: Chafarinas: El ayer y el presente de unas islas olvidadas (I) / Editores de este número Antonio Bravo Nieto, Juan Antonio Bellver Garrido y Sonia Gámez Gómez.

José Megías Aznar, Introducción, 7-8.

Antonio Pineda Velasco, José Luis Barrera (Ilustre Colegio Oficial de Geólogos), “Geología de las Islas Chafarinas", 9-38.

Javier Guallart Furió (Museo Nacional de Ciencias Naturales -MNCN-CSIC-) e Isabel Afán Asensio (Estación Biológica de Doñana -EBD-CSIC-), "Los sistemas naturales en el archipiélago de las IslasChafarinas", 39-94.

Juan Antonio Bellver Garrido (Director Proyecto Chafarinas, Instituto de Cultura Mediterránea), "La prehistoria de las Islas Chafarinas a través de la arqueología”, 95-124.

Manuel Aragón Gómez (Profesor-tutor UNED, Instituto de Cultura Mediterránea), "De las tres ínsulas a Jafarín. Las Islas Chafarinas y su entorno en la antigüedad y Medievo”, 125-156.

Sonia Gámez Gómez (Profesora-tutora UNED, Instituto de Cultura Mediterránea), "Las Islas Chafarinas a través de la cartografía. Del siglo XVI a la ocupación”, 157-190.

Carlos Esquembri Hinojo (Asociación de Estudios Melillenses), "Las Islas Chafarinas, desde 1848 hasta finales del siglo XIX”, 191-220. 
Antonio Bravo Nieto (Profesor tutor UNED, Instituto Cultura Mediterránea), "Fortificaciones y arquitectura militar de las Islas Chafarinas durante el siglo XIX”, 221-262.

Aldaba, Revista del Centro Asociado a la UNED de Melilla, $\mathbf{n}^{\circ} 38,2013$, dedicado a: Chafarinas: El ayer y el presente de unas islas olvidadas (II) / Editores de este número Antonio Bravo Nieto, Juan Antonio Bellver Garrido y Sonia Gámez Gómez.

Carlos Esquembri Hinojo (Asociación de Estudios Melillenses), "La vuelta de Saturnino Jiménez y el contrabando de armas”, 9-42.

Francisco Narváez López (Investigador), “Obras e infraestructuras portuarias en las Islas Chafarinas", 43-88.

Mari Carmen Lechado Granados (Instituto de Cultura Mediterránea), "Sociedad y vida cotidiana en las Islas Chafarinas”, 89-128.

Santiago Domínguez Llosá (Instituto de Cultura Mediterránea), "Los deportados de Primo de Rivera”, 129-152.

Antonio Bravo Nieto (Profesor tutor UNED, Instituto de Cultura Mediterránea), “Un templo de tradición neoclásica en el Norte de África. La Iglesia de la Inmaculada Concepción de Chafarinas”, 153-196.

Jorge Joaquín Prieto Sánchez, José María Gil Hernández (Grupo de Regulares de Melilla n 52), "El cementerio de la Isla del Rey", 197-202.

José María Gil Hernández, (Grupo de Regulares de Melilla n 52), "La presencia de los Regulares y de otras unidades militares en las Islas Chafarinas (1888-2008)”, 203-210.

Juan Antonio Bellver Garrido, Antonio Bravo Nieto, Sonia Gámez Gómez (Instituto de Cultura Mediterránea), "Diez años del Instituto de Cultura Mediterránea en las Islas Chafarinas", 211-237.

Aldaba, Revista del Centro Asociado a la UNED de Melilla, $\mathbf{n}^{\circ}$ 39, 2014, dedicado a: Apuntes históricos: la medicina en el norte de África.

Ángel M. Hernández Cardona (Doctor en Ciencias Biológicas) y Antonio Bravo Nieto (Doctor en Historia del Arte UNED), "Un dictamen médico del siglo XVIII. La confrontación crítica entre los doctores Thomas Exarch y Joseph Guiral sobre Pedro Zermeño”, 9-25.

Joseph Guiral y Conejos y Thomas Exarch, "Facsímil del Juicio crítico del accidente, que padece Don Pedro Zermeño, litigado entre los doctores D. Joseph Guiral y Conejos y Don Thomas Exarch", 27-78.

Ángel Manuel Hernández Cardona (Académico correspondiente de la Real Academia de Medicina de Cataluña), "Médicos y cirujanos presentes en el Sitio de Melilla, (1774-1775)", 79-119. 
Ángel Manuel Hernández Cardona (Doctor en Ciencias Biológicas) y Sonia Gámez Gómez (Profesora Historia UNED), "Un informe de Magín Berdós y Blasco a mediados del siglo XIX sobre los hospitales de Melilla, Peñón de Vélez de la Gomera y Peñón de Alhucemas”, $121-139$.

Francisco Javier Martínez Antonio (Investigador postdoctoral Marie Curie, SPHERE, CNRSUniversité Paris Diderot, Francia), "Vísperas de menos: la producción científica de los médicos españoles en Marruecos antes del Protectorado (1884-1906)”, 141-174.

Abdelmalik El Barkani Abdelkader (Doctor en Medicina y Cirugía, Neurocirujano), "Algunos aspectos de la acción sanitaria durante el Protectorado de España en Marruecos”, 173-205.

Pere Miret Cuadras (Doctor en Medicina), "Memorias de un médico en el Protectorado español de Marruecos a mediados del siglo XX”, 207-270.

\section{Aldaba, Revista del Centro Asociado a la UNED de Melilla, nº 40, 2015.}

Alejandro Tiana Ferrer (Rector de la UNED), "Preámbulo”, 9 - 10.

Juan José Imbroda Ortiz (Presidente de la Ciudad Autónoma de Melilla), "Presentación”, 11-12.

Antonio Bravo Nieto (Director de la revista Aldaba, director del Centro UNED Melilla), "La revista Aldaba, un nuevo número y un antiguo compromiso", 13-15.

José Megías Aznar (Director de la revista Aldaba (1983-2015), Secretario del Centro UNED Melilla), "Aldaba (1983-2015), una revista pluridisciplinar con un especial interés por Melilla y su entorno", 19-29.

Blas Jesús Imbroda Ortiz (Profesor tutor de Derecho Penal del Centro UNED Melilla, Decano del Ilustre Colegio de Abogados de Melilla), "La carrera de Derecho en el Centro UNED Melilla”, 31-54.

Manuel Aragón Gómez (Profesor tutor de Historia Antigua Universal del Centro UNED Melilla), "Sifax, el rey númida Masaesilio en los pasajes de Tito Livio”, 57-76.

Isabel Ma Migallón Aguilar (Licenciada en Geografía e Historia, UNED), "La población de Melilla en 1756. Ratificación de la Virgen de la Victoria como Patrona”, 77-104.

José Luis Barrera Morate (Geólogo, miembro de la International Commision on the History of Geological Sciences (INHIGEO), “Lucas Fernández Navarro. El primer geólogo español que pisó las islas Chafarinas”, 105-128.

Francisco Narváez López (Profesor tutor de Derecho Internacional Público del Centro UNED Melilla) “Orígenes del topónimo Río de Oro”, 129-146.

Juan Corbalán de Celis y Durán (Académico correspondiente de la RAC Valenciana) "Los servicios del capitán Miguel de Perea en la armada de guarda de la flota de Indias”, 149-180. 
Emilie D’Orgeix (Maitre de conférences en histoire de l'art Université Bordeaux-Montaigne), “Quelques considérations sur les traceurs de plans dans l'Amérique coloniale aux XVII et XVIII siècles: l'exemple des fondations urbaines en Nouvelle-France”, 181-196.

Pedro Luengo, (Profesor de la Universidad de Sevilla, King's College London), "Fortificaciones musulmanas en Joló: Resistencia, adaptación y reinterpretación de la guerra mo- derna occidental”, 197-212.

Jaime Vergara Muñoz (Doctor Arquitecto) y Miguel Martínez Monedero (Doctor Arquitecto, Universidad de Granada), "La zagüía Sidi Ali Ben Handuch de la Medina de Arcila (Marruecos)", 213-233.

Claudio Verdugo Lamarche (Arquitecto, miembro de la Unión Internacional de Arquitectos, antiguo profesor de la Escuela de Arquitectura de Rabat, Instituto de Urbanística Universidad de Valladolid), “Un arquitecto de origen español”, 235-259.

Sonia Gámez Gómez (Profesora tutora de Métodos y Técnicas de Investigación Histórica del Centro UNED Melilla), “Aldaba (1983-2015). Índices de la revista, nº 1 a 40”, 263-298. 



\section{Índice General de autores}

A

Aguayo, Rosario, 28

Aguirre García, Dolores, 1

Ahmed Aziza, Mimoun, 19

Ahmed Raha, Rachid, 19, 21, 27

Aiche, Boussad, 33

Akalay Naser, Mustafa, 16

Albasanz Mata, Encarnación, 26

Albert i Mas, Abel, 31

Aldrich, Mark, 28

Algora Weber, María Dolores, 31

Alías Rodríguez, Juana, 5, 9

Álvarez Calleja, María Antonia, 10, 12

Álvarez Martínez, José María, 30

Álvarez Vázquez, Manuel, 22

Antón, José Antonio, 27

Aparici Marino, Roberto, 7

Aragón Gómez, Manuel, 37, 40

Aranda Doncel, Juan, 26

Aserin Farache, Coty, 36

Auñón Manzanares, Luisa, 22, 26

Avilés Fernández, Miguel, 21

Ayllón Díaz, Jesús, 32

B

Ballesteros Jiménez, Soledad, 4, 11

Bardisa, Teresa, 7

Barrio Fernández de Luco, Claudio A., 5, 9 , 16,30
Barrera Morate, José Luis, 37, 40

Bautista Vilar, Juan, 26

Bellón Cazabán, Juan Alfredo, 21

Bellver Garrido, Juan Antonio, 37, 38

Benguigui Ley, Simón, 2, 6

Bernard Da Costa, Ana, 31

Benarroch, Alicia, 1, 6

Berlanga Fernández, Inmaculada, 31

Blanco López, José Luis, 22

Blas Guerrero, Andrés de, 20

Boge Pineda, Ma del Águila, 31

Borreguero García, Epifanio, 31

Boticario Boticario, Consuelo, 36

Boukous, Ahmed, 19

Bouzalmate, Hussein, 19, 21

Bravo Nieto, Antonio, 4, 5, 9, 14, 15, 33, 34, 37, 38, 39, 40

Bredt-Kriszat, Cristina, 28

Brock, Jeanette M., 28

Bueno Soto, Francisco Javier, 34

Bunes Ibarra, Miguel Ángel de, 25, 26

Burgos Madroñero, Manuel, 31

C

Cabello, Encarna, 1

Cabo Hernández, José Manuel, 3, 5, 13, 27

Cáceres Sánchez, Manuel, 23

Calderón, Lucas, 16

Calvo Buezas, Tomás, 29

Calzado Puertas, José Manuel, 1

Camero Pérez, Carmen, 12 
Campa, Annunziata O., 28

Cano Moreno, Jorge, 29

Cantón Fernández, Laura, 3

Carabelli, Romeo, 33

Carpintero, Helio, 11

Casado González, María, 32

Castro Cid, Benito de, 32

Castro Martos, M $^{\text {a }}$ Pilar, 25

Chaloukh, Mimunt, 19

Chicharro Chamorro, Antonio, 23

Chtatou, Mohamed, 19

Cobos, Mercedes, 28

Collado Mena, Carlos, 2

Colonas, Vassilis, 33

Corbalán de Celis y Durán, Juan, 40

Cotarelo, Ramón, 20

Crespo, Ricardo, 3

Cristófol de Alcaraz, Federico, 6

Cruz, J. M. de la, 14

\section{D}

Dankwardt, Hans-Ludwig, 22

Delgado, Feliciano, 4

Delgado Cobos, Inmaculada, 31

Delgado Pinto, José, 32

Díez Sánchez, Juan, 15, 21

D’Orgeix, Emilie

Domínguez, José, 27

Domínguez Llosá, Santiago, 3, 22, 26, 38

Domínguez Rey, Antonio, 23

Dormido, Sebastián, 14

Doudoh, Hassan, 19

Driessen, Henk, 3

\section{E}

El Barkani Abdelkader, Abdelmalik, 39

Escámez Pastrana, Antonio Manuel, 13

Escámez Pastrana, Marisa, 35

Escudero Uribe, Hanif, 36

Espinosa, Manuel, 14

Esquembri Hinojo, Carlos, 37, 38

Exarch, Thomas, 17, 39

F

Fernández, Miguel, 3

Fernández de Castro y Pedrera, Rafael, 9

Fernández de la Torre, José Luis, 4, 16, 21, 23, 25, 26

Fernández García, Ana María, 28

Fernández Montalvo, Rafael, 24

Fernández Trespalacios, José Luis, 11

Fernández Uriel, Pilar; 30, 36

Ferrari, Marta Beatriz, 28

Ferrer Benimeli, José Antonio, 9

Figueroa, Juan de, 17

Fredriksson, Ulf, 27

G

Gaite Pastor, Jesús, 26

Galera Andreu, Pedro, 21

Gallego Aranda, Salvador, 15, 16

Gallego Picó, Alejandrina, 36

Gámez Gómez, Sonia, 37, 38, 39, 40

García Alonso, $\mathrm{M}^{\mathrm{a}}$ Josefina, 5

García Ayala, Jesús A., 35 
García Baena, Pablo, 16

García Carrascosa, Miguel, 2

García Felipe, Ilde, 31

García Salama, José Javier, 16

García Velasco, Marcos M., 5

Garcinuño Martínez, Rosa María, 36

Gil Hernández, José $\mathrm{M}^{\mathrm{a}}$, 38

Gilbert Maceda, María Teresa, 10

Godoli, Ezio, 33

Gómez Barceló, José Luis, 26, 34

Gómez Bernardi, J. Mª 2

Gómez Serrano, Pilar, 30

Gómez Tabanera, José Manuel, 28

González, Alfredo, 28

González Bueno, Antonio, 13

González Fanjul, Genoveva, 31

González Fernández, Virgilio, 35

González Gómez, David, 36

González Gravioto, Carlos, 26

González Cravioto, Enrique, 9

González Escudero, Carmen, 12

González García, Juan Antonio, 3

González Reyes, Antonio Francisco, 25

González Ruíz, José María, 8

González Sánchez, José Javier, 5

González Sánchez, José Manuel, 22

González Sorroche, Francisca, 5

González Vázquez, Jesús Leonardo, 6

Granda Vera, Ángel, 10, 27

Granados Pérez, Carlos, 24

Guallart Furió, Javier, 37

Guerrero Ayuso, Víctor, 30
Guerrero Salazar, Susana, 28

Guiral y Conejos, Joseph, 39

Gutiérrez Cruz, Rafael, 21

Gutiérrez González, Rocío, 8

Gutiérrez Pellejero, Javier, 2

Gutiérrez Román, Isabel, 12

\section{H}

Hammouti, Abdeluahab, 19

Hassan Yahia, Jalifa, 29

Hernández Cardona, Ángel Manuel, 39

Hernández Hernando, Pilar, 36

Hernández Noguera, Concepción, 29

I

Imbernón Muñoz, Francisco, 27

Imbroda Ortiz, Blas Jesús, 18, 40

Imbroda Ortiz, Juan José, 40

J

Jilali, Said, 19

Jiménez Morales, María Isabel, 28

Junquera de Estéfani, Rafael, 32

K

Kaddour, Cadi, 19

Kassou, Abderrahim, 33

L

Lara Castaño, Ana Isabel, 29

Lara Peinado, Federico, 30

Laoukili, Montaser, 34 
La Torre Merino, José Luis, 25

Lattuca, Ada, 28

Lechado Granados, $M^{\mathrm{a}}$ Carmen, 38

Levy, León, 3, 5, 8

Linhares Borges, María Eliza, 28

López Belmonte, José Luis, 27; 29

López Bueno, José María ,35

López-Casanova, Arcadio, 23

López Martín, Javier, 34

López Pardo, Fernando, 30

Luengo, Pedro, 40

Lupiáñez, José, 23

M

Madariaga, $M^{a}$ Rosa de, 19

Marcos Casquero, $\mathrm{M}^{\mathrm{a}}$ del Carmen, 2

Marcos del Cano, Ana María, 32

Martín Corrales, Eloy, 9

Martín Rodríguez, Eustaquio, 7

Martínez, Pedro Pascual, 28

Martínez Albarracín, Carmen A., 31

Martínez Alcázar, Javier, 28, 31

Martínez Antonio, Francisco Javier, 39

Martínez Gámez, María Soledad, 29

Martínez Monedero, Miguel, 40

Martínez Morán, Narciso, 32

Mata, Marta, 2

Mayoral del Amo, Juan Francisco; 29

Mayorga, Juan, 11

Megías Aznar, José, 4, 9, 13, 15, 33, 34, 35, 40

Merinero Martín, María Jesús, 31

Metair, Kouider, 34
Migallón Aguilar, Isabel $\mathrm{M}^{\mathrm{a}}, 40$

Miguel Beriarin, Íñigo de, 32

Mir Berlanga, Francisco, 25

Miragaya García, Gonzalo ,6

Miras, José Salvador, 9

Miret Cuadras, Pere, 39

Miret García, Ma Teresa, 31

Miró, Emilio, 23

Moga Romero, Vicente, 2, 3, 4, 5, 9; 15, $16 ; 17,19$

Mohamed Laarbi, Alí, 15, 16, 22

Mohar Betancourt, Luz María, 28

Molina García, María José, 29

Molina Martínez, Miguel, 4

Montero Herrero, Santiago, 30

Montgomery Hart, David, 19

Monjaras-Ruiz, Jesús, 28

Monjas Hernández, Oñez, 31

Monga, Luigi, 28

Montabes Pereira, Juan, 20

Montero Madrid, Rosa María, 5

Montoya Puertas, María Isabel, 1

Morala Martínez, Paulina, 5

Morales Navarro, Julián, 10

Morales y Reyes, Luis, 9

Morán Rodríguez, M ${ }^{\mathrm{a}}$ Ángeles, 31

Moratinos Bernardi, Paloma, 15, 16

Morgenstern de Finkel, Sara, 7

Moufra, Naimia, 19

Moya, Carlos, 8

Muñoz Corbalán, José Miguel, 21

Muñoz Domínguez, José, 6 


\section{$\mathbf{N}$}

Narváez López, Francisco, 38, 40

Navarrete Urieta, José María, 18

Navarro Madrid, Ángel, 31

\section{O}

Ollero Tassara, Andrés, 32

Orozco Pardo, Guillermo, 1

$\mathbf{P}$

Palacios Alcalde, María, 21

Palacios Romero, Francisco J., 31

Palomera Parra, Isabel, 26

Palomo, $\mathrm{M}^{\mathrm{a}}$ del Pilar, 23

Parejo Delgado, María Josefa, 31

Pastor, Manuel, 20

Pastor Pastor, Brígida, 28

Payá Bernabé, José, 21

Paz Sánchez, Manuel de, 9

Perales Larios, Pedro J., 4

Perea Vázquez, María Jesús, 28

Pérez González, Ángel, 16

Pérez de Colosía Rodríguez, M ${ }^{a}$ Isabel, 22, 26

Pérez Luño, Antonio Enrique, 32

Pérez Roja, Francisco Javier, 33

Perpén Rueda, Adoración, 15

Picardo, Osvaldo, 28

Pineda Velasco, Antonio, 37

Pinillos, José Luis, 11

Pinto Molina, María, 10
Ponce Gómez, Adela A., 16

Posac Mon, Carlos, 9, 22, 26

Prieto Sánchez, Jorge Joaquín, 38

Puerta Luis, Luis-Román, 24

Puigpelat Martí, Francesca, 32

\section{Q}

Quiles Faz, Amparo, 28

$\mathbf{R}$

Rabdano, Lioudmila, 28

Raoui, Samir, 34

Reder Gadow, Marion, 21, 25, 26

Riaño López, Ana María, 1, 4, 5, 12

Rico Botella, Silvia, 31

Rico Martín, Ana María, 29

Rincón Ríos, Francisco, 23

Rizo Gutiérrez, Teresa, 1, 3

Rivera Garrido, Agueda, 28

Roales-Nieto y Azañón, Amalia, 28, 31

Rodríguez de la Flor, Fernando, 22

Rodríguez López, Manuel, 18

Rodríguez Martínez, Jaime, 13

Rodríguez Puget, Joaquín, 6, 25

Rojas Ruiz, Gloria, 29

Ros, Anna, 27

Rubio Gandía, Miguel Ángel, 28

Ruiz Alcaín, Ignacio, 22

Ruiz de la Parte, María Teresa, 28

Ruiz Vadillo, Enrique, 18, 24 
S

Sacristán Lucas, Ana, 7

Sáez Cazorla, Jesús, 9

Sáinz, Hermógenes, 8

Salafranca Ortega, Jesús F. , 5, 9, 15, 22; 28

Salvo Tierra, Ángel Enrique, 13

Samaranch Kirner, Francisco, 2

Sánchez de Horcajo, Juan José, 6

Sánchez Fernández, Sebastián, 27; 29

Sánchez Suárez, María Ángeles, 29

Sanmartín Solano, Ginés, 5

Santiago y Miras, María Ángeles, 31

Saro Gandarillas, Francisco, 1, 3, 5, 9, 15, 22

Sarompas Hernández, Luis, 25

Sepúlveda Muñoz, Isidro, 28

Serrano, Joseph, 17

Sierra Gil de la Cuesta, Ignacio, 24

Soares Dulci, Octavio, 28

Soria Pérez, Manuel, 16

Suances Marcos, Manuel, 12

Summers Gámez, Joaquín, 14

T

Tellería, José Luis, 14

Terki-Hassaine, Ismet, 25

Teruel, José, 23

Tiana Ferrer, Alejandro, 40

Torreblanca Roldán, María Dolores, 21

Torrejón Chaves, Juan, 26

Torres Chamorro, Sol, 31

Torres Santomé, Jurjo, 7

\section{U}

Uchen, Daniel, 16

$\mathrm{V}$

Valero, Ana Rita, 28

Valverde Martín, José Ignacio, 19

Vannini de Gerulewicz, Marisa, 31

Varela, Encarnación, 2

Vázquez Hoys, Ana María, 30

Vega Martín, Celia, 28

Vélez, Rafael, 16

Vera Aparici, Jorge, 26

Vera Delgado, Ana María, 22, 25

Verdugo Lamarche, Claudio, 40

Vergara Muñoz, Jaime, 40

Vidal García, Marciano, 32

Villanova Valero, José Luis, 31

Volait, Mercedes, 33

W

Wahnón Bensusan, Sultana, 1, 23

Wohrer, Anne-Marie, 28

Y

Yacine, Tssadit, 19

Yus Ramos, Rafael, 5

Yuste Gijalba, Francisco Javier, 10

Z

Zapata Navarro, Ana, 12

Zarandona Fernández, Juan M., 31

Zozaya, Juan 